\title{
Data-driven models for short-term thermal behaviour prediction in real buildings
}

\author{
Francesco Ferracuti ${ }^{\mathrm{a}}$, Alessandro Fonti ${ }^{\mathrm{a}}$, Lucio Ciabattoni ${ }^{\mathrm{a}}$, Stefano Pizzuti ${ }^{\mathrm{b}}$, Alessia \\ Arteconi $^{\mathrm{c}}$, Lieve Helsen ${ }^{\mathrm{d}}$, Gabriele Comodia,* \\ ${ }^{a}$ Universitá Politecnica delle Marche, Via Brecce Bianche 1, Ancona, 60131, Italy \\ ${ }^{b}$ ENEA, Via anguillarese 301, Rome, 00123, Italy \\ ${ }^{c}$ Universitá eCampus, Via Isimbardi 10, Novendrate (CO), 22060, Italy \\ ${ }^{d}$ KU Leuven, Celestijnenlaan 300 - bus 2421, Leuven, 3001, Belgium
}

\begin{abstract}
This paper presents the comparison of three data driven models for short-term thermal behaviour prediction in a real building, part of a living smart district connected to a thermal network. The case study building is representative of most of the buildings of the tertiary sector (e.g. offices and schools) built in Italy in the $60 \mathrm{~s}-70 \mathrm{~s}$ of the $20^{\text {th }}$ century. The considered building models are: three lumped element grey-box models of first, second and third order, an AutoRegressive model with eXogenous inputs (ARX) and a Nonlinear AutoRegressive network with eXogenous inputs (NARX). The models identification is performed by means of real measured data. Nevertheless the quantity and quality of the available input data, all the data driven models show good accuracy in predicting short-term behaviour of the real building both in winter and summer. Among the grey-box models, the third order one shows the best performance with a Root-Mean-Square Error (RMSE) in winter less than $0.5^{\circ} \mathrm{C}$ for a prediction horizon of 1 hour and a RMSE less than $1^{\circ} \mathrm{C}$ for a prediction horizon of 3 hours. The ARX model shows a maximum RMSE less than $0.5^{\circ} \mathrm{C}$ for a prediction horizon of 1 hour and a RMSE less than $0.8^{\circ} \mathrm{C}$ for a prediction horizon of 3 hours. The NARX network shows a maximum RMSE less than $0.5^{\circ} \mathrm{C}$ for a prediction horizon of 1 hour and a RMSE less than $0.9^{\circ} \mathrm{C}$ for a prediction horizon of 3 hours. In summer the RMSE is
\end{abstract}

\footnotetext{
The short version of the paper was presented at ICAE2016 on Oct 8-11, Beijing, China. This paper is a substantial extension of the short version of the conference paper.

${ }^{*}$ Corresponding author. Tel.: +39-071-220-4761; fax: +39-071-220-4770

Email address: g. comodi@univpm. it (Gabriele Comodi)
}

Preprint submitted to Applied Energy

April 18, 2017 
always lower than $0.4^{\circ} \mathrm{C}$ for all the models with a 3-hours prediction horizon. Other than typical control applications, the paper demonstrates that all the data driven models investigated can also be proposed as a powerful tool to detect some typologies of occupant bad behaviours and to predict the short-term flexibility of the building for Demand Response (DR) applications since they allow a good estimation of the building "thermal flywheel".

Keywords: Grey-box modelling, Black-box modelling, Demand Response, Bad behaviour occupant detection, Building "thermal flywheel", Building flexibility

\section{Introduction}

The residential sector accounts for about $40 \%$ of the total energy consumption [1], thus it is more and more important to put into action strategies for energy conservation and energy management in buildings. In this context, building energy models have a paramount importance because they allow predicting and, then controlling, the energy demand. In particular, building energy modelling is used for (i) energy efficiency and optimal control; (ii) demand side management (DSM) strategies; (iii) fault detection and energy conservation. With more detail, in order to increase the energy efficiency, besides refurbishment and use of new technologies, optimal control is a method to improve the overall system performance. Specifically, model predictive control (MPC) is an advanced control technique, based on a dynamic model of the building and aimed at determining the optimal control inputs [2]. MPC is used in energy demand management of buildings and it has shown good results for achieving high energy efficiency [3]. Moreover, MPC has an important application in demand side management framework, especially for demand response (DR) [4], which is intended as those actions whose purpose is the modification of final users load profile based on grid price signals. Indeed, building modelling is employed to quantify the available flexibility that a building can provide in demand response programs [5]. Eventually, given the importance of users behaviour on the amount of energy consumption [6], building energy models can also be used to detect e.g. users bad behaviours [7] and this piece of information is a means to increase the users awareness and then to affect their final energy 
use [8].

For all the above mentioned applications, the precision and accuracy of the model is crucial for its effectiveness. Especially in the case of MPC, the reliability influences the control performance [9], then the choice of the adopted model is essential. There are three categories of buildings energy systems models: white box, grey box and black box [8]. When building monitoring data are available, data driven grey box and black box models assume a remarkable role. Among them, reduced order grey-box models are particularly suitable in predictive control as they combine building physics and model structure knowledge typical of the white-box approach with the parameters estimation through measured data of a black-box approach [10]. Whereas possible simple black-box models are the linear AutoRegressive models with eXogenous inputs (ARX), as demonstrated by Yun et al. [11]. Touretzky and Patil [12] developed an ARX model to forecast power demand for building energy management, namely supervisory control and demand response. Ríos-Moreno et al. [13] investigated in what extent ARX and ARMAX, AutoRegressive Moving Average models with eXogenous inputs, could be used in order to predict the interior air temperature of a building. In the case they considered, the ARX models gave a better prediction of the temperature than the ARMAX models. Moreover, also nonlinear black-box models as NARX (Nonlinear AutoRegressive network with eXogenous inputs) have been used for this application by some authors [14]. Powell et al. [14] evaluated several different models to accurately forecast hourly loads for a district energy system up to 24 hours in advance. They found out that a NARX shows the best fit to data.

The identification procedure has a central role for the correctness of data driven models. Therefore it is necessary to minimize the prediction errors due, for example, to a misleading model identification procedure for unpredicted disturbances. Indeed a significant part of the difference between the model output and measured data may be due to unmeasured disturbances rather than model errors. During the identification procedure the effects of such disturbances should be separated from the other inputs effects. O'Dwyer et al. [15] developed a model for identifying building models (both high order and low order simulation models) from data in which significant unmeasured disturbances are present to be used within model predictive control strategies. 
The disturbances could be attributed to arbitrary events caused by the occupants or by uncertain data input. In order to address this issue Kwak et al. [16] developed a real-time building energy simulation to assess the energy consumption, while an MPC was established for control. Similarly Kim et al. [17] presented a method to obtain improved grey-box building models from closed loop data having significant unmeasured disturbances. They used lumped disturbance modelling approach to simultaneously estimate the building dynamics and dynamics of unmeasured disturbances. Moreover, in real time applications, besides the representation of disturbances, there is the problem of faulty sensors that collect experimental data and it is necessary to take this aspect into account during the choice of the best model structure and the identification procedure. Žáčeková et al. [18] used a Model Predictive Control Relevant Identification method (MRI) to address this problem. They showed that this kind of identification procedure is appropriate for real-life applications. The models they obtained by MRI method are (despite of poor quality of data) able to provide models that predict the zone temperature for 2 days ahead with a mean error approximately $0.3^{\circ} \mathrm{C}$ or less.

In the present work several models for short-term thermal behaviour prediction are analysed. The investigated models are grey-box models, ARX and NARX models, believed the most interesting on the basis of the above literature review. In particular three time horizons for short-term prediction are considered: 15 minutes, 1 hour and 3 hours. These short interval times are suitable for application e.g. in MPC or in fast demand response for ancillary services [5]. Purpose of this work is to critically analyse the identification process, based on data acquired in an existing building, rather than simulated data, as often done in literature [11, 19]. Indeed, the parameters of the models are here identified through measures of: indoor and outdoor air temperature, thermal and electrical load power and global horizontal irradiance. In particular practical issues, such as the amount of reliable data available, the sampling time and the presence of unpredicted disturbances, arising during the identification procedure of data-driven models in real applications are discussed. The comparison of the performance of the different models is also performed. Furthermore some possible applications of the proposed models are investigated. They include the detection of users bad behaviours, by comparing predicted and simulated data, and the assessment of the available flexibility 
that a building can offer to the grid in demand response frameworks, by predicting the temperature drift when no thermal power is supplied.

The remainder of the paper is organized as follows: Section 2 describes the real building test-case and the analysed data driven models; Section 3 illustrates the identification procedure; Section 4 shows the results of the identification procedure; in Section 5 main findings are discussed; finally, Section 6 summarizes the conclusions of the work.

\section{Materials and methods}

A smart building that belongs to a living smart district was considered as case study. This building is representative of most of the buildings of the tertiary sector (e.g. offices and schools) built in Italy in the 60s-70s of the $20^{\text {th }}$ century. Data obtained from sensors installed in the building are used to identify data driven models: three lumped element grey-box models (of first, second and third order) and two black-box models, the first is the linear ARX and the second is the nonlinear model NARX. The identification procedure of each model is illustrated and their performance is compared. Eventually some applications of the proposed building energy models are discussed.

\subsection{Test Case: the "Smart Village" and the F70 Building}

The Smart Village is a small smart district located within the ENEA research centre of Casaccia in Rome and comprises 8 single storey buildings (progressively numbered F66 $\div$ F73) connected to a thermal network supplied by a thermal plant (F85) (Fig. 1a). The buildings are intended for office use and are connected each other and to the common thermal plant by a heating-cooling thermal network.

The analysis carried out in this study focuses on the single storey building F70. F70 is a single floor building 36.50 meters long, 10.80 meters wide and 3 meters high; the roof is horizontal. Fig. $1 \mathrm{~b}$ shows the plan of the F70 building: the eighteen offices are highlighted in blue; the restroom in purple, the corridor in grey and the thermal substation in red. The thermal substation contains the three-way valve that connects the build-

ing to the district heating/cooling network and the thermal energy meter that acquires 
Table 1: Description of materials and thickness of the external walls and of the flat roof.

\begin{tabular}{|l|l|l|}
\hline & Material & Thickness [m] \\
\hline \multirow{5}{*}{ External walls } & Concrete & 0.06 \\
& Expanded perlite board (EPB) & 0.05 \\
& Concrete & 0.16 \\
& Polistyrene & 0.02 \\
& Plasterboard & 0.01 \\
\hline \multirow{5}{*}{ Flat roof } & Plaster & 0.01 \\
& Concrete & 0.05 \\
& Air & 0.20 \\
& Concrete & 0.05 \\
& Polyethylene & 0.01 \\
& Expanded perlite board (EPB) & 0.05 \\
& Light concrete & 0.03 \\
& Concrete & 0.05 \\
\hline
\end{tabular}

real time data of thermal energy provided to the building. The red asterisk in Fig. $1 \mathrm{~b}$ indicates the position of the only temperature measuring point in the corridor. Table 1 reports materials and thickness of the external walls and of the flat roof. Internal walls are made of bricks $8 \mathrm{~cm}$ thick and covered by plaster. Windows are single glass with aluminum frame. Table 2 reports the list of sensors, and their characteristics, installed to monitor the quantities that were used for the identification process of the models: i) indoor temperature, that is the quantity that the models aim to predict (output); ii) thermal power (afterwards named thermal gains); ii) internal gains, iii) solar gains and iv) external temperature. In particular the thermal power was measured by a thermal energy meter consisting of a water flow rate sensor and two thermocouples PT100, one for the inlet and one for the outlet water temperature. Weather data (i.e. global horizontal irradiance and outdoor temperature) were measured by a weather station installed in the smart village area. In order to avoid gap in weather data, Meteonorm database [20] for the period under investigation was used as backup, mainly for global horizontal irradiance. The weather station of Meteonorm database was "Rome Ciampino airport". As proposed in Reynders et al. [19], the global horizontal irradiance from the weather station is used as an alternative to the effective solar gains, which are difficult to obtain, and the building electrical power is used as an alternative input for the effective user gains. 


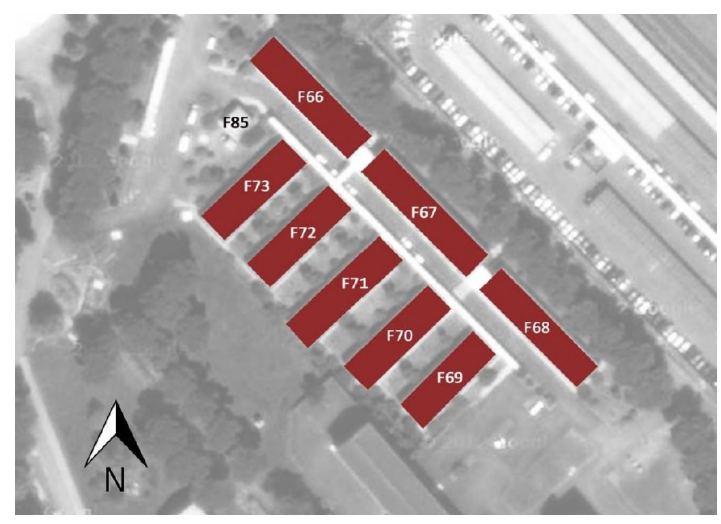

(a)

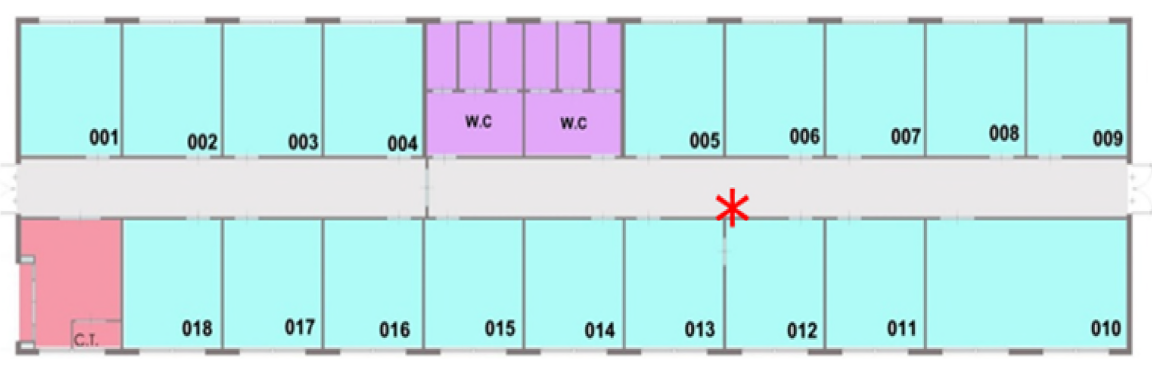

(b)

Figure 1: The Smart Village (a) and the plan of the one storey building F70 (b).

\subsection{Models description}

The following subsections report a short description of the grey-box, ARX and NARX models used for indoor temperature prediction in the considered real building.

\section{Grey-box lumped element models}

The lumped element models here analysed are derived by resistance-capacitance (RC) networks analogous to those used to describe electric circuits. Fig. 2 shows the three considered models and reports the parameters and the input-output quantities.

In the first order model (Fig. 2a) the entire thermal mass of the building is lumped to a single capacity and no distinction is made between the structural mass and the indoor air mass. The 2nd order model (Fig. 2b) takes into account this difference by including 
Table 2: Sensors of interest installed in each building of the Smart-Village.

\begin{tabular}{lll}
\hline Quantities & Sensors & Accuracy \\
\hline Indoor Temperature & Energy Team XM11 & Accuracy: $\pm 0.3{ }^{\circ} \mathrm{C}$. \\
Electric Power & Energy Team X-Meter & Accuracy: $0.5 \%$ \\
Water flow rate & Energy Team ET-MS2500 & Accuracy: $0.1 \%$ \\
& ET-ML110 & \\
Water temperature & Energy Team ET-ML311 & Accuracy $\pm 0.2 \%$ \\
\hline
\end{tabular}

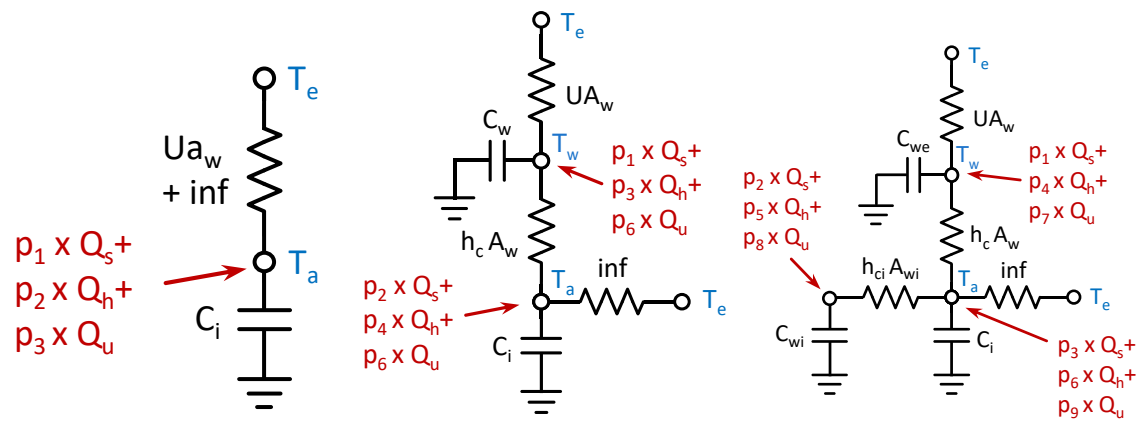

(a)

(b)

(c)

Figure 2: Low order RC building models. (a) first order, (b) second order, (c) third order.

a second capacity. The 3rd order model (Fig. 2c) instead, has 3 different capacities for the envelope $\left(C_{w e}\right)$, the internal walls $\left(C_{w i}\right)$ and the indoor air $\left(C_{i}\right)$ [19].

For these models the inputs are: the outdoor air temperature $\left(T_{e}\right)$, solar gains $\left(Q_{s}\right)$, internal gains $\left(Q_{u}\right)$ and thermal gains $\left(Q_{h}\right)$. The thermal gains represent the thermal power introduced by the heating/cooling system. Indeed the heating/cooling system is not directly modelled, but the fan coils thermal load is taken into account as an input signal [19]. The observation variable is the indoor air temperature $\left(T_{a}\right)$. For all the model orders, solar gains, internal gains and thermal gains are distributed over the capacities. The distribution coefficients are assumed to be constant and are identified within the identification process.

The models in Fig. 2 2 are parametrized and so can be treated as grey-box models. A grey-box model consists of a set of continuous stochastic differential equations formu- 
lated in a state space form together with an output equation as follows [19, 21]:

$$
\begin{aligned}
d \boldsymbol{X}(t) & =\boldsymbol{A}(\boldsymbol{\theta}) \boldsymbol{X}(t) d t+\boldsymbol{B}(\boldsymbol{\theta}) \boldsymbol{U}(t) d t+\boldsymbol{\sigma}(\boldsymbol{\theta}) d \omega \\
\boldsymbol{Y}(t) & =\boldsymbol{C}(\boldsymbol{\theta}) \boldsymbol{X}(t)+\boldsymbol{D}(\boldsymbol{\theta}) \boldsymbol{U}(t)+\boldsymbol{\varepsilon}
\end{aligned}
$$

where $\boldsymbol{X}(t)$ is the state vector of the dynamic system, $\boldsymbol{U}(t)$ is a vector containing the measured inputs of the system, $\sigma(\cdot)$ is the process noise matrix which describes how the disturbances affect the system and $\omega$ is a Wiener process. The measured output of the system $\boldsymbol{Y}(t)$ is given as a function of the states $\boldsymbol{X}(t)$ and the inputs $\boldsymbol{U}(t) . \boldsymbol{\varepsilon}$ is the measurement error. $\boldsymbol{\theta}$ are the parameters to be estimated.

Referring to the second order model depicted in Fig. $2 b$ as example, the general state-space form (Eq. (1)-(2) ) can be written as follows:

$$
\begin{gathered}
\boldsymbol{X}(t)=\left[\begin{array}{ll}
T_{a} & T_{w}
\end{array}\right]^{T} \quad \boldsymbol{U}(t)=\left[\begin{array}{llll}
T_{e} & Q_{s} & Q_{h} & Q_{u}
\end{array}\right]^{T} \\
\boldsymbol{A}(\boldsymbol{\theta})=\left[\begin{array}{cc}
-\left(\frac{1}{R_{2} C_{i}}+\frac{1}{R_{3} C_{i}}\right) & \frac{1}{R_{2} C_{i}} \\
\frac{1}{R_{2} C_{w}} & -\left(\frac{1}{R_{1} C_{w}}+\frac{1}{R_{2} C_{w}}\right)
\end{array}\right] \quad \boldsymbol{B}(\boldsymbol{\theta})=\left[\begin{array}{cccc}
\frac{1}{R_{3} C_{i}} & \frac{p_{1}}{C_{i}} & \frac{p_{3}}{C_{i}} & \frac{p_{5}}{C_{i}} \\
\frac{1}{R_{1} C_{w}} & \frac{p_{2}}{C_{w}} & \frac{p_{4}}{C_{w}} & \frac{p_{6}}{C_{w}}
\end{array}\right] \\
\boldsymbol{C}(\boldsymbol{\theta})=\left[\begin{array}{ll}
1 & 0
\end{array}\right] \quad \boldsymbol{D}(\boldsymbol{\theta})=\left[\begin{array}{llll}
0 & 0 & 0 & 0
\end{array}\right]
\end{gathered}
$$

where $R_{1}=1 / U A_{w}, R_{2}=1 / h_{c} A_{w}, R_{3}=1 /$ inf are the thermal resistences for walls, convection and infiltration respectively. The parameters $p_{1}$ to $p_{6}$ are the input distribution coefficients. All the components belonging to the vector $\boldsymbol{\theta}$ :

$$
\boldsymbol{\theta}=\left(R_{1}, R_{2}, R_{3}, C_{i}, C_{w}, p_{1}, p_{2}, p_{3}, p_{4}, p_{5}, p_{6}\right)
$$

can be estimated by means of the identification procedure as explained in detail in the next section. The first and third order models can be represented in a similar way. The differences are in the state vector dimension and in the number of parameters to be identified.

\section{ARX model}

The autoregressive model with exogenous inputs is a linear model defined by the equation [22]:

$$
A(z) y(k)=B(z) u(k)+v(k)
$$


with $A(z)$ and $B(z)$ denoting polynomials with respect to time-shift operator $z: A(z)=$ $1+a_{1} z^{-1}+\cdots+a_{n_{a}} z^{-n_{a}}$, and $B(z)=b_{0}+b_{1} z^{-1}+\cdots+b_{n_{b}} z^{-n_{b}}$. The ARX model considered in this study for training and 1-step ahead prediction can be mathematically represented as:

$$
\begin{aligned}
T_{a}(k) & =-\sum_{i=1}^{n_{a}} a_{i} T_{a}(k-i)+\sum_{j=0}^{n_{b}} b_{1 j} T_{e}\left(k-j-n_{k}\right)+ \\
& +\sum_{j=0}^{n_{b}} b_{2 j} Q_{s}\left(k-j-n_{k}\right)+\sum_{j=0}^{n_{b}} b_{3 j} Q_{h}\left(k-j-n_{k}\right)+\sum_{j=0}^{n_{b}} b_{4 j} Q_{u}\left(k-j-n_{k}\right)+v(k)
\end{aligned}
$$

where $k=n T_{c}$ denotes time, $n \in \mathbb{Z}$, sampling period $T_{c}$ and $a_{i}, b_{1 j}, b_{2 j}, b_{3 j}$ and $b_{4 j}$ denote the unknown model parameters. $n_{a}, n_{b}$ and $n_{k}$ are the orders of the model (so called hyper-parameters) associated with output, inputs and dead time in the system, respectively. $v(k)$ represents a white noise independent of past measurements. A prediction of the system output at time instant $k$ from past measured outputs is obtained by omitting $v(k)$ :

$$
\begin{aligned}
\hat{T}_{a}(k) & =-\sum_{i=1}^{n_{a}} a_{i} T_{a}(k-i)+\sum_{j=0}^{n_{b}} b_{1 j} T_{e}\left(k-j-n_{k}\right)+ \\
& +\sum_{j=0}^{n_{b}} b_{2 j} Q_{s}\left(k-j-n_{k}\right)+\sum_{j=0}^{n_{b}} b_{3 j} Q_{h}\left(k-j-n_{k}\right)+\sum_{j=0}^{n_{b}} b_{4 j} Q_{u}\left(k-j-n_{k}\right)
\end{aligned}
$$

where $\hat{T}_{a}(k)$ is the estimated indoor air temperature and it is considered as a 1-step ahead prediction, because $\hat{T}_{a}(k)$ is computed from measured outputs up to the time instant $k-1$.

In this study $n_{k}$ is fixed to 0 , whereas $n_{a}$ and $n_{b}$ were each varied over the range 1 to 12 (equivalent to a time horizon between 15 minutes and 3 hours).

Two structures of ARX models are used to estimate the indoor air temperature in the studied test case, one is the 1-step ahead (or short-term) prediction model, as defined previously in Eq. (8), and the other is the simulation model (or long-term prediction 
model or k-step ahead prediction) as shown in Eq. (10):

$$
\begin{aligned}
\hat{T}_{a}(k) & =-\sum_{i=1}^{p} a_{i} \hat{T}_{a}(k-i)-\sum_{i=p+1}^{n_{a}} a_{i} T_{a}(k-i)+\sum_{j=0}^{n_{b}} b_{1 j} T_{e}\left(k-j-n_{k}\right)+ \\
& +\sum_{j=0}^{n_{b}} b_{2 j} Q_{s}\left(k-j-n_{k}\right)+\sum_{j=0}^{n_{b}} b_{3 j} Q_{h}\left(k-j-n_{k}\right)+\sum_{j=0}^{n_{b}} b_{4 j} Q_{u}\left(k-j-n_{k}\right)
\end{aligned}
$$

where no past output measurements up to $p$ are used in predicting the indoor air temperature.

\section{NARX network}

A nonlinear autoregressive network with exogenous inputs is a special case of Recurrent Neural Network (RNN), which proved to be a very successful modeling tool for nonlinear systems and especially time series [23]. NARX networks converge faster, are less likely to develop long-term dependencies and typically have better generalization abilities than other networks [23]. The NARX structure considered in this study for training and 1-step ahead prediction can be mathematically represented as:

$$
\begin{aligned}
T_{a}(k) & =f\left[T_{a}(k-1), \ldots, T_{a}\left(k-n_{a}\right) ; T_{e}\left(k-n_{k}\right), \ldots, T_{e}\left(k-n_{k}-n_{b}\right) ;\right. \\
& Q_{s}\left(k-n_{k}\right), \ldots, Q_{s}\left(k-n_{k}-n_{b}\right) ; Q_{h}\left(k-n_{k}\right), \ldots, Q_{h}\left(k-n_{k}-n_{b}\right) ; \\
& \left.Q_{u}\left(k-n_{k}\right), \ldots, Q_{u}\left(k-n_{k}-n_{b}\right)\right]+v(k)
\end{aligned}
$$

The nonlinear mapping $f$ is generally unknown and can be approximated, for example, by a standard Multilayer Perceptron (MLP) network. The resulting architecture is then called a NARX network. A prediction of the system output at time instant $k$ from past measured outputs is obtained by omitting $v(k)$ :

$$
\begin{aligned}
\hat{T}_{a}(k) & =f\left[T_{a}(k-1), \ldots, T_{a}\left(k-n_{a}\right) ; T_{e}\left(k-n_{k}\right), \ldots, T_{e}\left(k-n_{k}-n_{b}\right) ;\right. \\
& Q_{s}\left(k-n_{k}\right), \ldots, Q_{s}\left(k-n_{k}-n_{b}\right) ; Q_{h}\left(k-n_{k}\right), \ldots, Q_{h}\left(k-n_{k}-n_{b}\right) ; \\
& \left.Q_{u}\left(k-n_{k}\right), \ldots, Q_{u}\left(k-n_{k}-n_{b}\right)\right]
\end{aligned}
$$

The NARX network training can be carried out in Series-Parallel (SP) mode or Parallel (P) mode. In particular in the first case, the output regressor is formed only by actual values of the system output, while in the second case, estimated outputs are fed back 
and included in the output regressor. In this paper the SP mode is considered because it gives best prediction results [24].

In all the underlying experiments, the NARX network was simulated using the Matlab Neural Network Toolbox. As concerns the network structure, NARX network with one hidden layer was considered and the hidden and output neurons with a hyperbolic tangent transfer function and a linear transfer function, respectively, were used. Levenberg-Marquardt training algorithm was chosen, because it is highly recommended as a first-choice and it is faster than other algorithms although it requires more memory [25]. The training was stopped after the number of training epochs exceeded 200 or if the error gradient reached $10^{-7}$.

In this study $n_{k}$ is fixed to 0 , whereas the hyper-parameters $n_{a}$ and $n_{b}$ were each varied over the range 1 to 12 (equivalent to a time horizon between 15 minutes and 3 hours) and the number of neurons in the hidden layer varies over the range 1 to 10. Two structures of NARX networks are used to estimate the indoor air temperature in the studied test case, one is the 1-step ahead (or short-term) prediction model, as defined previously in Eq. [11, and the other is the simulation model (or long-term prediction model or k-step ahead prediction) as shown in Eq. [13):

$$
\begin{aligned}
\hat{T}_{a}(k) & =f\left[\hat{T}_{a}(k-1), \ldots, \hat{T}_{a}(k-p) ; T_{a}(k-p-1), \ldots, T_{a}\left(k-n_{a}\right) ;\right. \\
& \left.T_{e}\left(k-n_{k}\right)\right), \ldots, T_{e}\left(k-n_{k}-n_{b}\right) ; Q_{s}\left(k-n_{k}\right), \ldots, Q_{s}\left(k-n_{k}-n_{b}\right) ; \\
& \left.\left.Q_{h}\left(k-n_{k}\right)\right), \ldots, Q_{h}\left(k-n_{k}-n_{b}\right) ; Q_{u}\left(k-n_{k}\right), \ldots, Q_{u}\left(k-n_{k}-n_{b}\right)\right]
\end{aligned}
$$

\section{Identification procedure}

Data pre-processing is the first step before the identification procedure. In particular, for grey-box models and ARX, data detrend is performed. This data processing operation helps to estimate more accurately linear models and overcome their inability to capture arbitrary differences between the input and output signal levels. Whereas, for NARX identification, data are normalized in the range $[-1,1]$ since a sigmoid function is considered in the hidden layer. In all experiments the initial conditions of each model to predict $k$-step ahead model output are considered as zero. 
For the grey-box models and ARX, the System Identification Toolbox in Matlab was used on the training dataset (see Section 3.1 for dataset partitioning) to estimate the unknown parameters for each possible model order. The parameter identification procedure was conducted using the greyest function in Matlab. This function leads to the maximum likelihood estimates and uses three different algorithms as search method for the iterative parameter estimation: the Gauss-Newton direction, the LevenbergMarquardt and the steepest descent gradient search method. At each iteration greyest chooses the search method to obtain the highest reduction in error.

In the NARX model, instead, the optimal values of the model parameters were estimated using the Neural Network Toolbox in Matlab and the training data set for every combination of the model orders.

The orders of the models (first, second and third for the grey-box model; $n_{a}, n_{b}$ for the ARX and NARX models) and the number of neurons of the NARX in the hidden layer were selected using the cross-validation technique as described in Section 3.1

\subsection{Cross-Validation}

A popular method for testing the performance of a prediction model to be identified is cross-validation. This technique separates the data into multiple sets: the training sets

and the validation sets. Training sets are used to train models. Then the trained models are applied to the data of the validation sets. The model parameters are selected to optimize the performance based on validation sets. In this work the hyper-parameters to be identified with this methodology are $n_{a}, n_{b}$ for ARX and NARX, the number of neurons in the hidden layer for NARX and the order of the grey-box model. Cross-validation is proven to limit problems like overfitting and presence of outliers and it allows to obtain generalized models [26, 27]. In this paper, the blocked cross-validation is used and in particular 5-fold cross-validation is applied on data that are not partitioned randomly, but sequentially into five sets.

The cross-validation procedure is particularly useful when models are identified on the basis of real measured data. Indeed, real data can contain corrupted values due to unpredicted occupants behaviour or faulty sensors and this affects the identification procedure [18]. In real practice it could be difficult to detect possible outliers in the 
measured data and remove them from the dataset before using it. The main advantage of cross-validation procedure is its ability to mitigate the presence of outliers and it was applied in this work to demonstrate once again its usefulness in such contexts.

\subsection{Data}

The data used for the identification process are retrieved from the Smart Village centralized database. Such database collects the sensor measurements coming from all the cluster buildings and the thermal plant with a fixed sample time of $900 \mathrm{~s}$. Measured data are available since September 2014. Useful data for the identification procedure are selected considering periods in which there are no missing data. The monitored period for winter goes from 8 January 2015 to 4 February 2015 and for summer from 1 July 2015 to 31 July 2015 . The input signals of the winter and summer periods used to train the identification models are shown in Fig. 3 .

Data are partitioned sequentially into five sets (i.e., Training-set and Validation-set) for 5-fold cross-validation, as previously described.

After identification, the models were validated by means of the following indicators:

- the RMSE-values at 15-min (1-step);

- the level of fit (FIT);

- the auto-correlation of the residuals.

The RMSE (root mean square error) is the objective function to be minimized both for training and validation sets. RMSE is defined as follows:

$$
R M S E=\left(\frac{1}{N} \sum_{k=1}^{N} e(k)^{2}\right)^{\frac{1}{2}}
$$

where $\mathrm{N}$ is the number of samples and $e(k)=T_{a}(k)-\hat{T}_{a}(k)$ represents the difference between the indoor temperature predicted by the simulation model and the measured temperature, i.e. the model prediction error. FIT-values are the percent normalized root mean square errors and thus these summarize in percentage the model goodness of fit (similarly to RMSE). Finally, the level of the auto-correlation in the residuals shows if 


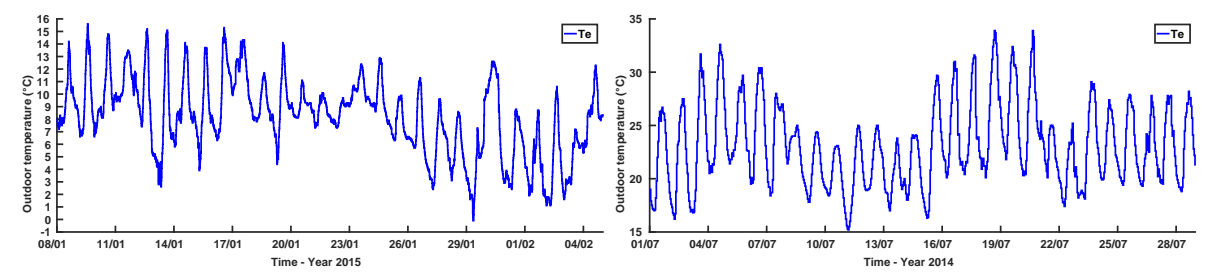

(a) Outdoor air temperature $\left(T_{e}\right)$ in winter season. $\quad$ (b) Outdoor air temperature $\left(T_{e}\right)$ in summer season.

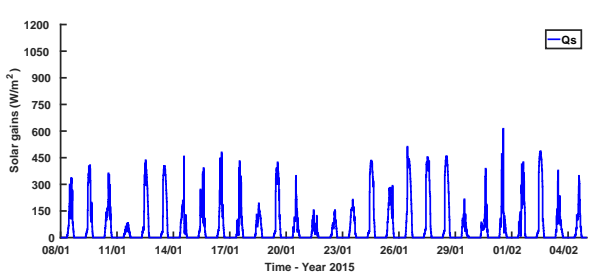

(c) Solar gains $\left(Q_{s}\right)$ in winter season.

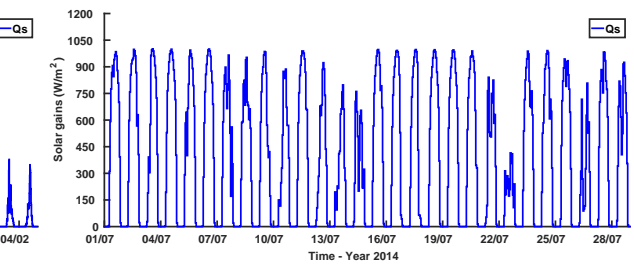

(d) Solar gains $\left(Q_{s}\right)$ in winter season.

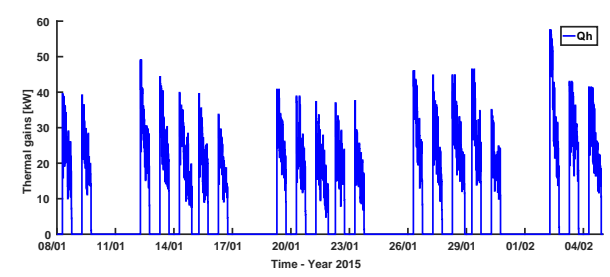

(e) Thermal gains $\left(Q_{h}\right)$ in winter season.

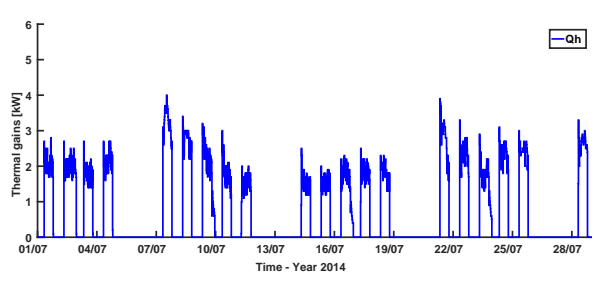

(f) Thermal gains $\left(Q_{h}\right)$ in summer season.

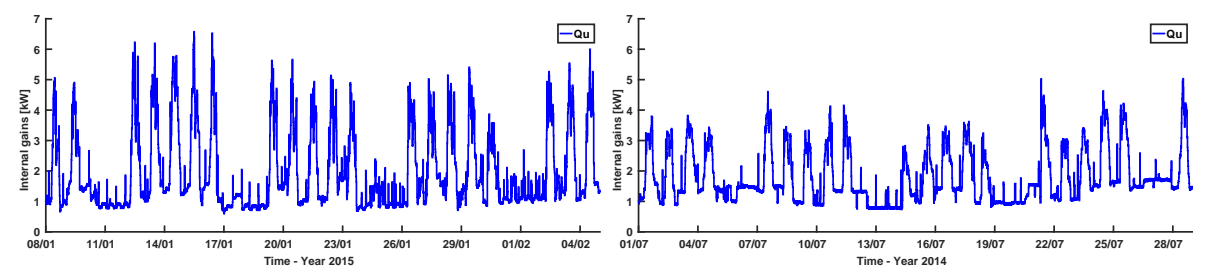

(g) Internal gains $\left(Q_{u}\right)$ in winter season.

(h) Internal gains $\left(Q_{u}\right)$ in summer season.

Figure 3: Input data for the model identification. 
the model explains well the dynamics contained in the dataset and if some dynamics of the real process cannot be properly taken into account.

\section{Results}

Table 3 and Table 4 present the identification results in terms of RMSE-values calculated on the winter and summer validation datasets respectively. With regards to the grey-box models, the minimum value of the RMSE for the 1-step prediction (15 minutes) is obtained in the third order model $\left(0.167{ }^{\circ} \mathrm{C}\right.$ in winter and $0.110^{\circ} \mathrm{C}$ in summer). The improvement of the third order model with respect to the second order model is limited, therefore, increasing the model complexity beyond the third order does not produce a significant improvement in accuracy. The third order model is therefore the best choice in terms of accuracy and complexity, although it can be noticed that even the simpler second order model presents a relatively low RMSE. This is in accordance with Reynders et al. [19], who highlighted the same behaviour in case of using only one observation variable, the indoor air temperature, considered a good choice for those models used in MPC or DR applications. In winter the RMSE-values for 1-hour ahead prediction of the 2nd and 3rd order grey-box models are close to $0.45^{\circ} \mathrm{C}$, while the 1 st order model presents a RMSE of $0.5^{\circ} \mathrm{C}$. In summer, instead, the difference among the different order models is small: the RMSE is $0.22^{\circ} \mathrm{C}$ for the third order and $0.24{ }^{\circ} \mathrm{C}$ for the second and first order for 1-step ahead prediction. In case of longer horizon the discrepancy among the models is slightly more evident. In winter the RMSE-values, in case of 3-hours ahead prediction, are less than $0.95{ }^{\circ} \mathrm{C}$ for $2 \mathrm{nd}$ and 3rd grey-box models, while the 1st order model presents a RMSE more than $1{ }^{\circ} \mathrm{C}$. In summer, for the same time horizon, the RMSE is about $0.30^{\circ} \mathrm{C}$ for the $3 \mathrm{rd}$ order model and almost $0.37^{\circ} \mathrm{C}$ for the 1 st order model. Note that the latter values are of the same order of magnitude of the accuracy of the temperature sensor (see Table 2). The results show as the 2nd and 3rd order models are better than the 1st order model for longer prediction horizon. FIT-values are also adequate since they are higher than $93 \%$ in winter and of $83 \%$ in summer for all the analysed cases.

Considering the other linear model analysed, i.e. the ARX model, it shows a bet- 
ter performance than the grey-box models in terms of fitness on validation datasets. Indeed, the RMSE-values are generally smaller than the values of the other models, especially for longer-term prediction (at 3-hours ahead prediction the maximum RMSE relative difference between ARX and grey-box models is about $11 \%$ in winter and 5\% in summer). FIT-values are also good since they are close to $94 \%$ in winter and to $84 \%$ in summer.

The NARX networks show better results in terms of fitness and RMSE for 1-step ahead prediction (as maximum in winter the RMSE is 14\% lower than the ARX and $21 \%$ lower than the grey-box), but on the other hand, the RMSE-values are worse than linear models for more than 1-step ahead prediction.

Table 3: Cross-validation results: RMSE-values $\left({ }^{\circ} \mathrm{C}\right)$ on Validation-set for each model.

\begin{tabular}{|c|c|c|c|c|c|}
\hline \multicolumn{6}{|c|}{ Validation-set } \\
\hline $\begin{array}{l}\text { Prediction } \\
\text { horizon }\end{array}$ & $\begin{array}{c}\text { ARX } \\
n_{a}=2, n_{b}=1\end{array}$ & $\begin{array}{l}\text { Greybox } \\
\text { 1st order }\end{array}$ & $\begin{array}{l}\text { Greybox } \\
\text { 2nd order }\end{array}$ & $\begin{array}{l}\text { Greybox } \\
\text { 3rd order }\end{array}$ & $\begin{array}{c}\text { NARX } \\
n_{a}=2, n_{b}=1 \\
\text { neurons }=1\end{array}$ \\
\hline RMSE 1-step $\left({ }^{\circ} \mathrm{C}\right)$ & 0.159 & 0.178 & 0.168 & 0.167 & 0.139 \\
\hline RMSE 1 h $\left({ }^{\circ} \mathrm{C}\right)$ & 0.423 & 0.500 & 0.453 & 0.453 & 0.431 \\
\hline RMSE 3 h $\left({ }^{\circ} \mathrm{C}\right)$ & 0.777 & 1.040 & 0.863 & 0.855 & 0.879 \\
\hline FIT \% 1 step & 93.91 & 93.08 & 93.48 & 93.49 & 94.40 \\
\hline
\end{tabular}

With regards to the prediction capabilities of the three models, Fig. 4 and Fig. 5 report a comparison between measured and predicted indoor air temperature with a prediction horizon of 15 minutes, 1 hour and 3 hours for winter and summer case respectively. In particular Fig. 4 shows that the worst correspondences occur during working hours when there are temperature peaks. The latter aspect is related to unpredicted disturbances in the model and is further discussed in the next section. As expected on the basis of the RMSE values reported in Table 3 and Table 4 , the prediction error increases when the prediction horizon increases.

Figs. 6a 6c and 6e show the auto-correlations of 1-step prediction residuals for the grey-box models calculated with a lag of 25 time steps (1 lag is 15 minutes) for the winter case. Blue solid lines indicate a $99 \%$ limit of confidence. The autocorrelation levels in the 2 nd and 3rd order models are closer to the confidence limit, meaning that these models describe better the building dynamics in the dataset. The autocorrela- 

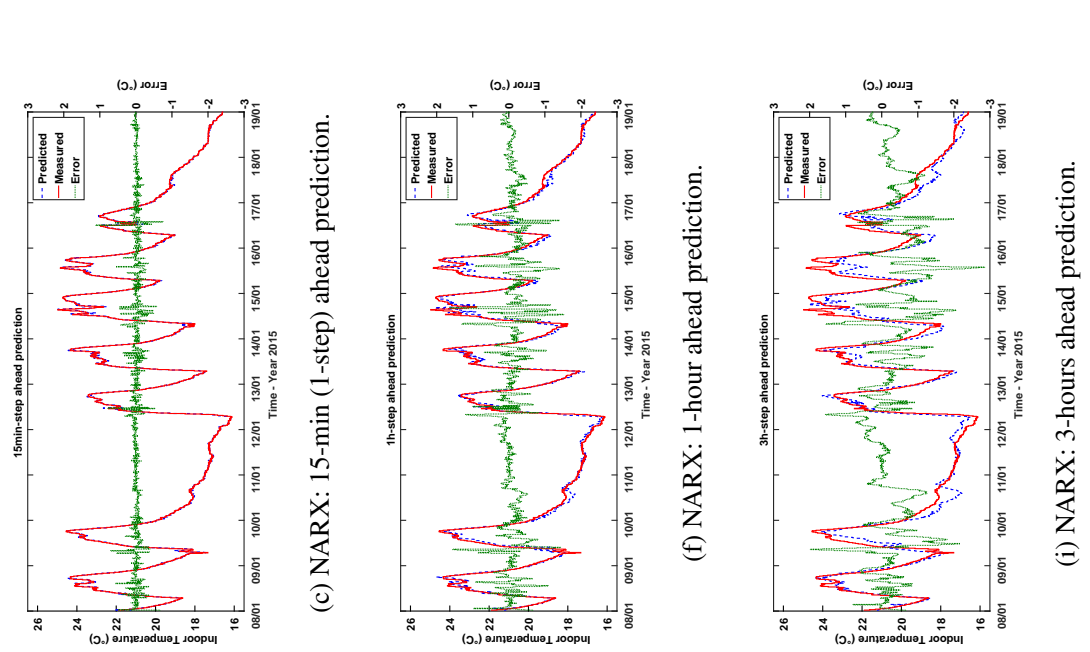

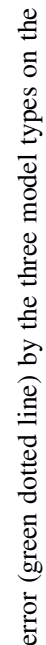
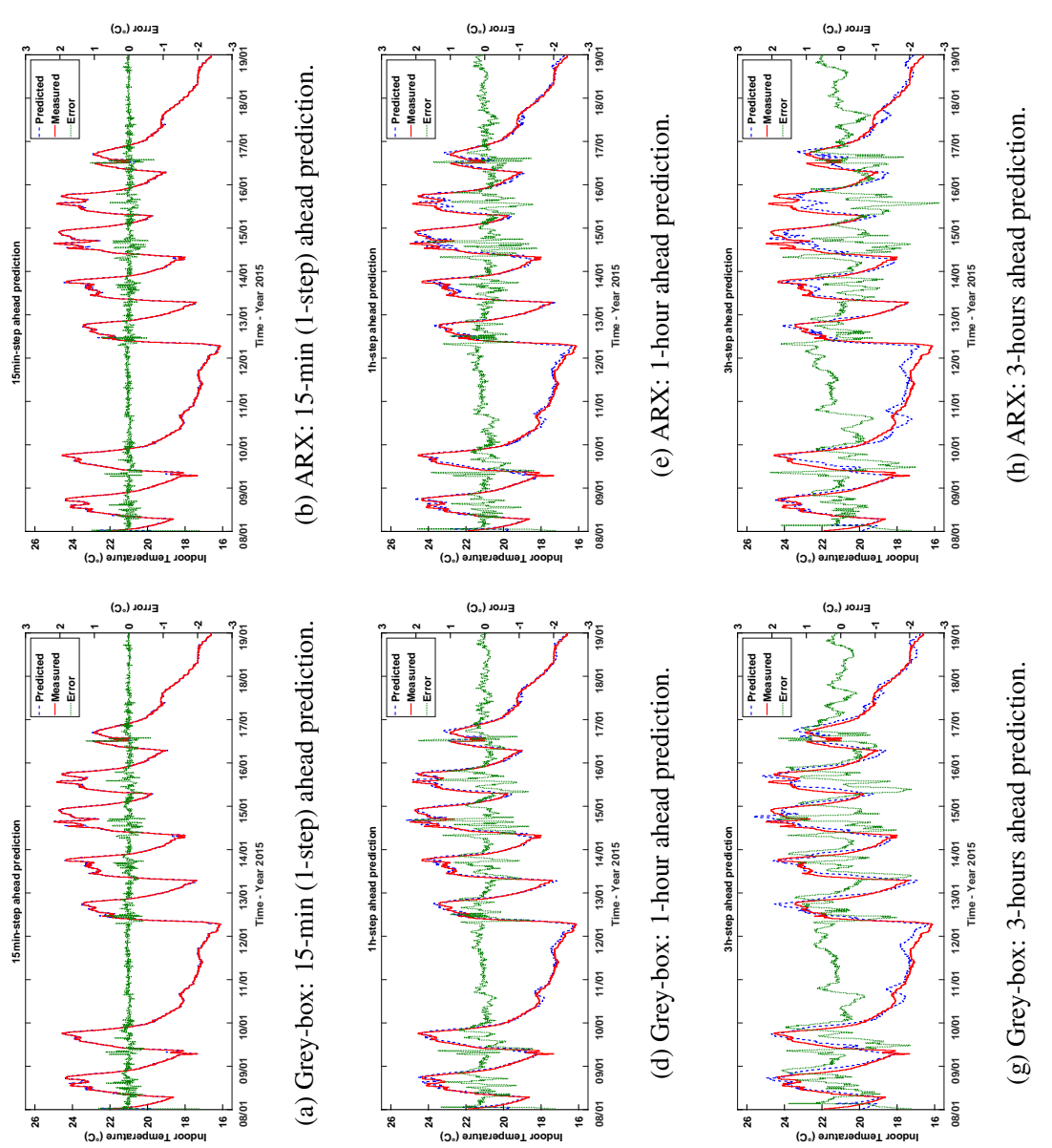

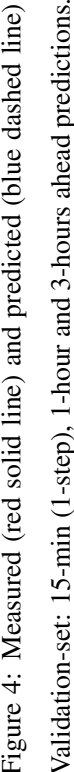


tion plot of the 3rd order model is the best with respect to the other grey-box models. Figs. 6b. 6d and 6f show, instead, the auto-correlations of 1-step prediction residuals for the summer case. As also visible from the RMSE values, the three models behave more similarly among them than in the winter case and the auto-correlation residuals confirm this attitude.

Figs. 6g, 6h, 6i] and 6j show the auto-correlation of 1-step prediction residuals for ARX and NARX models in winter and summer. These values suggest a similar dynamic of the two models. The points outside of the confidence limits of all residuals are related to the behaviours not represented by the models.

Concluding, all the considered models can predict pretty well the indoor air temperature behaviour in the considered time frames. Among them the ARX model provides slightly better results than the other models, especially for longer-term prediction horizon, while the NARX has the lower RMSE for 1-step ahead prediction. The ARX model has also the advantage to have a simple structure and to need a lower number of parameters to be identified, then it represents a good option for real implementation in e.g. MPC systems. In summer all the models provide an improved prediction capability, that is mainly due to the quality of available data and to the way the represented system behaves. It is evident that the quality of real data affect the prediction accuracy and it is a crucial aspect during identifications by means of measurements. Considering how the RMSE values increase with time, these models suit better when the prediction horizon is not too long.

Table 4: Cross-validation results: RMSE-values $\left({ }^{\circ} \mathrm{C}\right)$ on Validation-set for each model.

\begin{tabular}{|c|c|c|c|c|c|}
\hline \multicolumn{6}{|c|}{ Validation-set } \\
\hline $\begin{array}{c}\text { Prediction } \\
\text { horizon }\end{array}$ & $\begin{array}{c}\text { ARX } \\
n_{a}=5, n_{b}=1\end{array}$ & $\begin{array}{l}\text { Greybox } \\
\text { 1st order }\end{array}$ & $\begin{array}{l}\text { Greybox } \\
\text { 2nd order }\end{array}$ & $\begin{array}{l}\text { Greybox } \\
\text { 3rd order }\end{array}$ & $\begin{array}{c}\text { NARX } \\
n_{a}=5, n_{b}=1 \\
\text { neurons }=1\end{array}$ \\
\hline RMSE 1-step $\left({ }^{\circ} \mathrm{C}\right)$ & 0.109 & 0.128 & 0.110 & 0.110 & 0.105 \\
\hline RMSE 1 h $\left({ }^{\circ} \mathrm{C}\right)$ & 0.226 & 0.239 & 0.225 & 0.224 & 0.229 \\
\hline RMSE 3 h $\left({ }^{\circ} \mathrm{C}\right)$ & 0.331 & 0.355 & 0.318 & 0.317 & 0.359 \\
\hline FIT \% 1 step & 83.98 & 81.03 & 83.75 & 83.76 & 84.62 \\
\hline
\end{tabular}




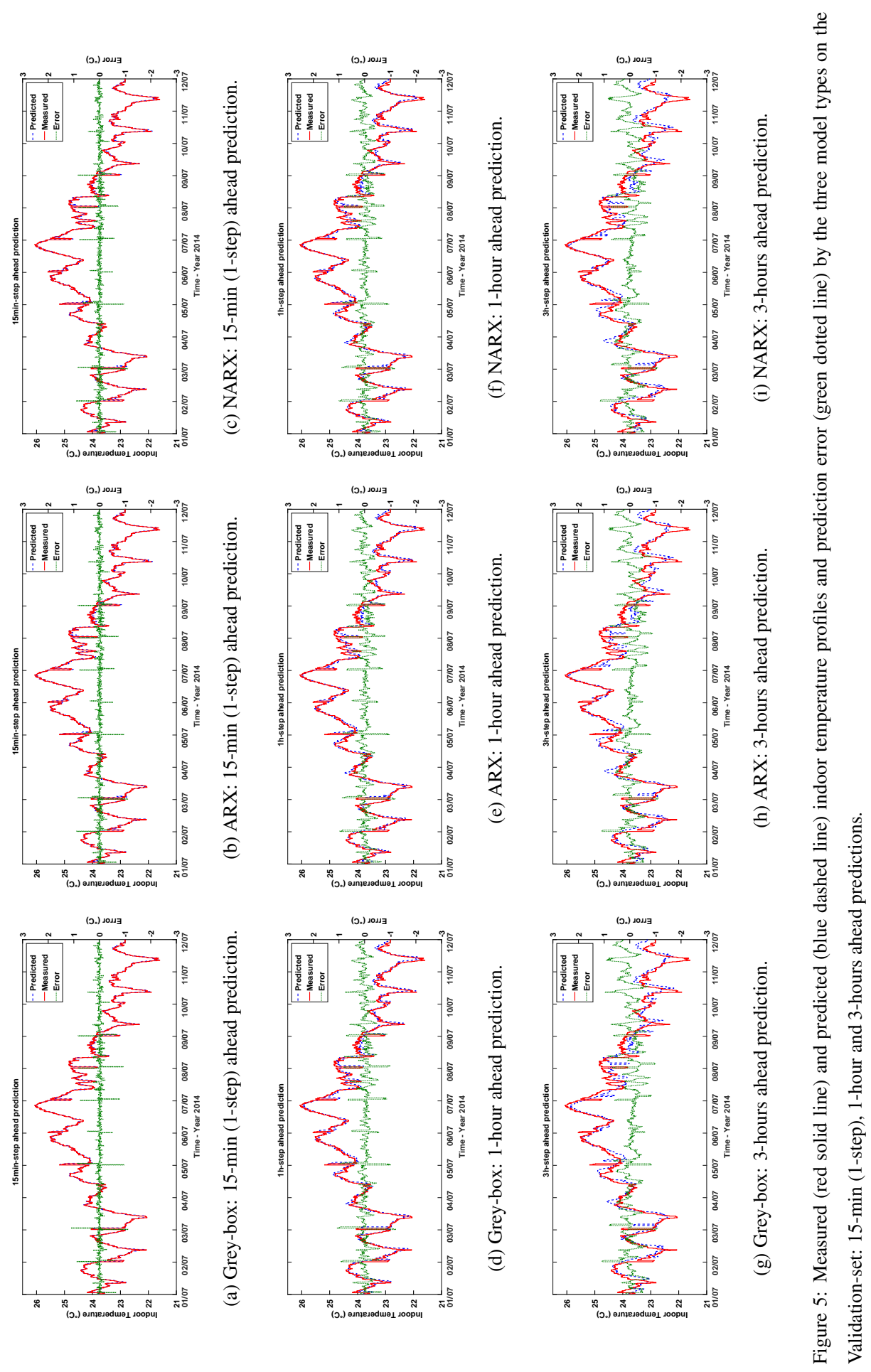




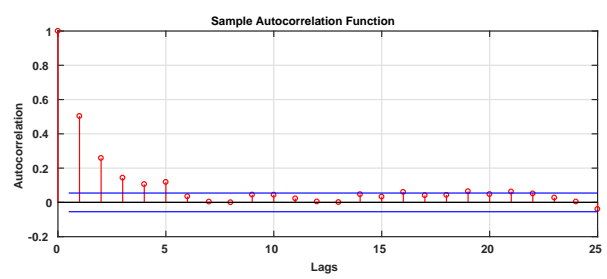

(a) 1st order Grey-Box trained on winter season.

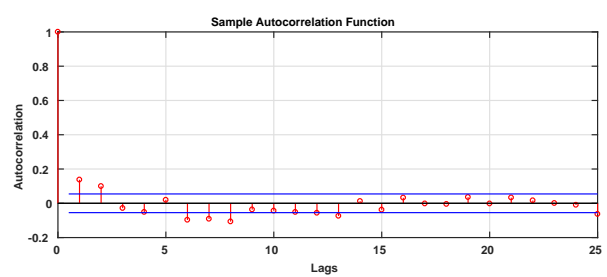

(c) 2nd order Grey-Box trained on winter season.

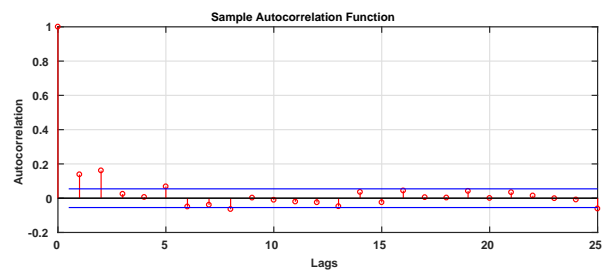

(e) 3rd order Grey-Box trained on winter season.

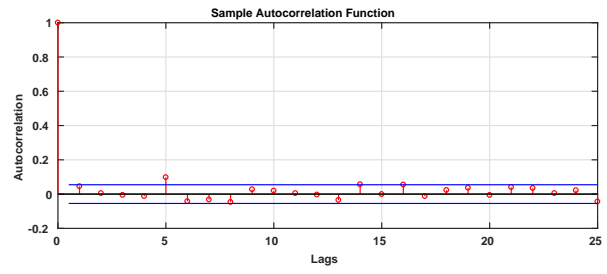

(g) ARX trained on winter season.

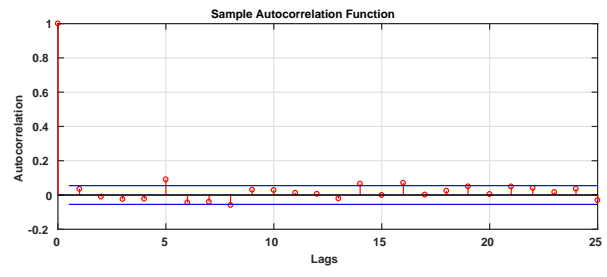

(i) NARX trained on winter season.

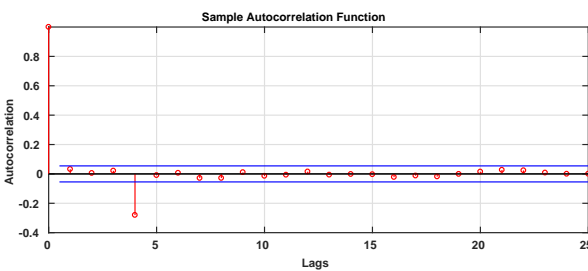

(b) 1 st order Grey-Box trained on summer season.

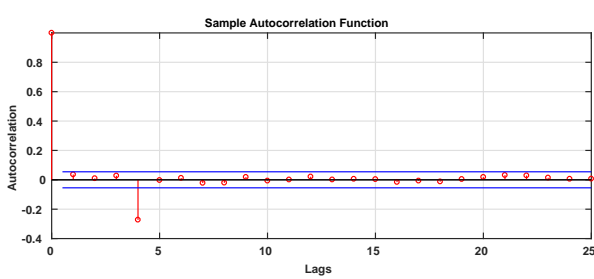

(d) 2nd order Grey-Box trained on summer season.

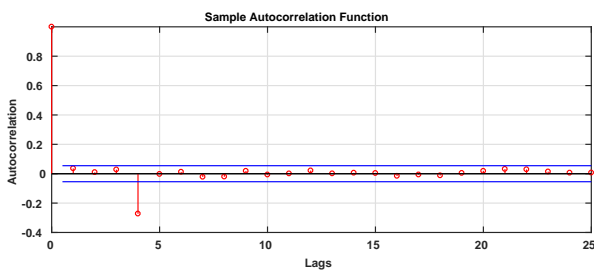

(f) 3rd order Grey-Box trained on summer season.

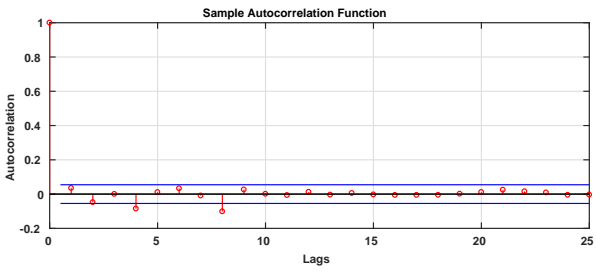

(h) ARX trained on summer season.

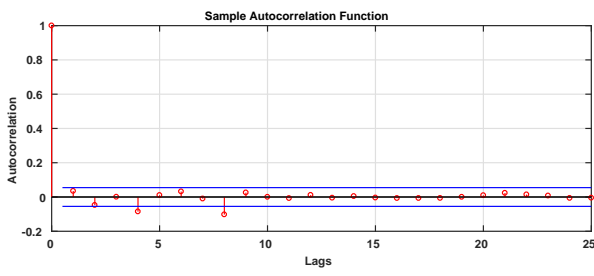

(j) NARX trained on summer season.

Figure 6: Residual autocorrelation with a lag of 25 ( 1 lag = 15 minutes) for the grey-box, ARX and NARX models. Blue solid lines indicate a $99 \%$ limit of confidence. 


\section{Comments and main findings}

\subsection{Identification issues}

Some general conclusions about the identification procedure in presence of real data can be drawn on the basis of the results for the analysed case study. Main critical issues that arose are about:

- Data availability and sensors position;

- Sample time;

- Disturbances and data outliers.

In order to have a proper identification procedure, it is necessary to have a certain amount of reliable data. In this case the recording period was about 1 month both in summer and winter. It demonstrated to be a reasonable period of time for a good identification. However the models obtained in this way are season-depending, meaning that they can be used only for the season in which they have been identified. A complete year round data set would be necessary to set up a general model reliable over the all year. The prediction accuracy obtained depends on the variable trend of the indoor temperature to be predicted, that makes difficult to use such models for long term simulation. Furthermore, regarding the position of the sensors to record the data used in the identification, having a single measuring point in the corridor for the indoor temperature as in this case, may not be adequate to describe the offices thermal behaviour. Thus, if the identified models are used for control purposes within the offices, the control would be poor. In this specific case the indoor temperature sensor was installed for monitoring purposes rather than control. Moreover, even if a detailed control in the building is not possible, the building model can be used for a higher level control to manage the thermal supply by means of the three-way valve that regulates the flow rate coming from the thermal network (see Section 2.1). However, the lack of a wide set of sensors in real applications can frequently occur and it represents a typical practical issue to be faced during process identification in reality.

The available data have a sample time of $900 \mathrm{~s}$. Such sample time affects the minimum prediction horizon of the models, thus if the models are used for control purposes, 
it is not possible to operate control actions for time steps shorter than 15 minutes, in this case. In the considered building that is equipped with fan coils, the sample time for thermal power may be too wide because of the low thermal inertia of these systems. Indeed, if fan coils switching on/off times are too fast, related measures may be affected by a major aliasing. In this case part of the thermal power dynamic is lost in the recorded measures and this cannot be taken into account by the identified models.

Eventually, the analysis of the prediction capabilities of the models (see Fig. 4) shows that there are specific moments when the prediction error is higher and they occur in case of suddenly spikes of the indoor temperature. Such high temperature values are outliers present in the measured dataset. As previously discussed, the cross validation procedure allows to identify the models also in presence of outliers, diminishing their influence. Thus the models are not able to represent these disturbances and it is acceptable in case of casual errors or erroneous behaviours that want to be put into evidence as in this case. Indeed, the reason for their presence is further investigated in the next section and they revealed to be useful for fault detections. Instead, in case the models are used for control purposes and the outliers are due to recurrent behaviours, the disturbances should be represented in the model in order to have reliable predictions and implement effective control actions.

\subsection{Users bad behaviour}

An outcome of the study is the ability of the data driven models, identified with the cross-validation procedure, to detect some typologies of occupant bad behaviours. Fig. 7 shows the anomalies detected using the ARX model for 1-hour ahead prediction. Actually, all the three models proved to be able to detect anomalies, but only the ARX case is represented for sake of conciseness. The anomalies are detected by a $99 \%$ limit of confidence and they are depicted with asterisk markers.

An in-depth analysis of the RMSE for all the three models showed that the highest differences between predicted and measured data happened systematically at specific times every week. Hence, a further investigation was done by cross-checking measured data with interviews with occupants and building managers and it was found that the anomalies corresponded to two main events related to occupants behaviour: 


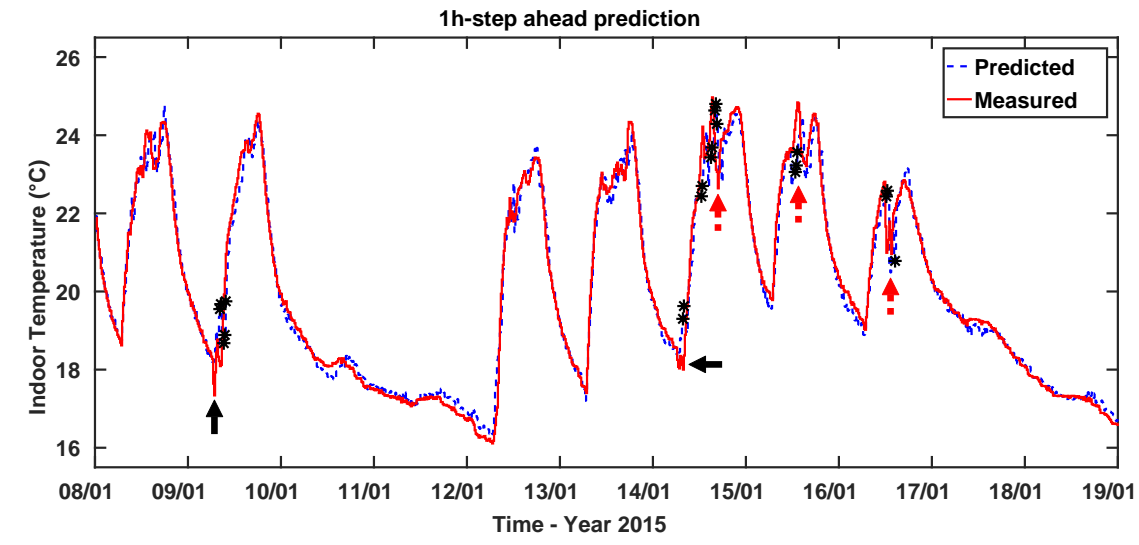

(a) Anomalies and bad behaviors for valdation data.

Figure 7: Anomalies and bad behaviors for 1-hour ahead prediction (ARX model).

the anomalies occurring early in the morning are due to windows and external doors opening during cleaning service; the anomalies occurring during lunch break are due to external door opening of people leaving the building and coming back shortly. In Fig. 7, indoor temperature rapid changes are indicated through black (solid) arrows and red (dotted) arrows: rapid temperature changes that occur in the morning are indicated by black arrows (windows and doors opening). The ones indicated through red arrows occur at lunch time (external door openings). The asterisk markers, which are not indicated by the arrows, are other behaviours and dynamics not well explained by the ARX model.

The identified data driven models could be used for the implementation of a real time bad behaviour detection warning system. It can contribute to raise occupant awareness: indeed, as resulted from the occupants interviews, the anomalies identified were due to a lack of awareness rather than to an actual bad behaviour. A similar tool is very useful for energy manager, e.g. to produce an energy reduction policy or to support a retrofitting strategy [28].

\subsection{DR applications}

Another interesting application of the identified models is related with their ability to provide a good estimation of the "thermal flywheel" of the building [5]. In particular, 
they demonstrated to predict in a satisfactory way the temperature profile once the heating system is switched off. Fig. 8 reports the trend of measured and predicted (ARX model) indoor temperature together with the thermal power provided to the building. Fig. 8 highlights the very good accordance of predicted and measured data. Thanks to the model it is possible, when the thermal power is null, to predict how long the heating system can be switched off before the minimum temperature setpoint is reached. As an example, Fig. 8 shows that the heating system of the building F70 was switched off from the afternoon of Friday $9^{\text {th }}$ of January (18:00) until Monday 12 $2^{\text {th }}$ (6:00 a.m.) morning. During this time the indoor temperature (corridor) progressively decreased from about $24^{\circ} \mathrm{C}$ (Friday at $17: 45$ ) down to $20^{\circ} \mathrm{C}$ (Friday evening at $23: 15$ ), $18{ }^{\circ} \mathrm{C}$ (Saturday morning at $11: 45$ ) and $16^{\circ} \mathrm{C}$ (Monday morning at 6:15). The temperature trend is related to the building "thermal flywheel", that can be used in DR application as a reserve of thermal power. For instance, in the case of Building F70, hypothesizing that the thermal power was provided by a heat pump instead of a district heating network and that the minimum required temperature set by occupants was $18^{\circ} \mathrm{C}$, the building heating system could be switched off providing the grid with an average reserve of flexibility of $7 \mathrm{kWe}$ (considering a $\mathrm{COP}=3$ ) and $84 \mathrm{kWh}$ (about 12 hours, at least). Given their accuracy, the presented data driven models could be used to implement short term MPC controls for DR application by acting on the indoor temperature set-points to control the power supplied to the HVAC system of the building.

\section{Conclusions}

This work investigated three data driven models that have been identified and validated on measured data coming from a living building, part of a smart district in Italy. The models are: three lumped element grey-box models of first, second and third order; a Nonlinear AutoRegressive network with eXogenous inputs (NARX); and an AutoRegressive model with eXogenous inputs (ARX) model. As far as the grey-box models are concerned, the RMSE values are less than $0.5^{\circ} \mathrm{C}$ for 1-hour prediction and close to $1{ }^{\circ} \mathrm{C}$ for 3-hours prediction in winter, while in summer they are about $0.3{ }^{\circ} \mathrm{C}$ for 3 hours prediction. The residual autocorrelation analysis shows that the grey-box models 


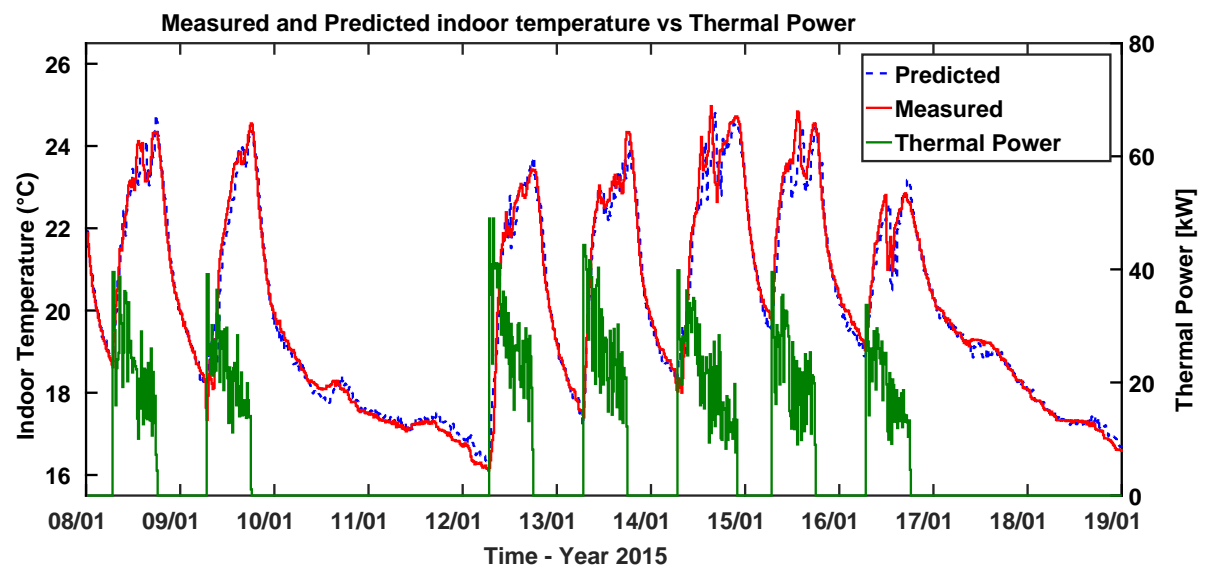

Figure 8: Trend of measured and predicted indoor temperature (ARX model) together with the thermal power provided to the building.

describe pretty well the building dynamics, especially the second and third order models, but underlines also that there are behaviours and approximations that the models cannot take into account. The identified ARX model shows a better performance than the other models in terms of fitness. In particular the ARX model has lower RMSE for longer-term prediction $\left(0.8^{\circ} \mathrm{C}\right.$ in winter and $0.3{ }^{\circ} \mathrm{C}$ in summer for 3-hours prediction). The NARX model behaves slightly worse than the other models when the time horizon increases, but better for 1-step ahead prediction $\left(0.139^{\circ} \mathrm{C}\right.$ in winter and $0.105^{\circ} \mathrm{C}$ in summer). However, in general all the considered models showed good accuracy in predicting short term behaviour of the real building under investigation. Furthermore, thanks to the cross-validation procedure used, data outliers do not affect the identification process and the models can be used to highlight unpredicted users bad behaviours (such as windows and external doors openings during cleaning service or lunch time) when real data distance too much from the predicted values. Finally these models can be used both for MPC applications and for estimating the "thermal flywheel" of the building when short-term DR actions want to be implemented. 


\section{Acknowledgements}

The data used in this study were kindly provided by ENEA, the Italian National Agency for New Technologies, Energy and Sustainable Economic Development, Casaccia Research Centre, Rome.

\section{References}

[1] EIA, How much energy is consumed in residential and commercial buildings in the united states?, 2016. URL: http://www.eia.gov/tools/faqs/faq.cfm? id=86\&t=1

[2] F. Oldewurtel, A. Parisio, C. N. Jones, D. Gyalistras, M. Gwerder, V. Stauch, B. Lehmann, M. Morari, Use of model predictive control and weather forecasts for energy efficient building climate control, Energy and Buildings 45 (2012) 15 $-27$.

[3] M. Maasoumy, M. Razmara, M. Shahbakhti, A. S. Vincentelli, Handling model uncertainty in model predictive control for energy efficient buildings, Energy and Buildings 77 (2014) 377-392.

[4] M. D. Knudsen, S. Petersen, Demand response potential of model predictive control of space heating based on price and carbon dioxide intensity signals, Energy and Buildings 125 (2016) 196 - 204.

[5] R. Yin, E. C. Kara, Y. Li, N. DeForest, K. Wang, T. Yong, M. Stadler, Quantifying flexibility of commercial and residential loads for demand response using setpoint changes, Applied Energy 177 (2016) 149 - 164.

[6] A.-L. Lindén, A. Carlsson-Kanyama, B. Eriksson, Efficient and inefficient aspects of residential energy behaviour: What are the policy instruments for change?, Energy Policy 34 (2006) 1918 - 1927.

[7] A. Giantomassi, F. Ferracuti, G. Puglia, A. Fonti, G. Comodi, Malfunction and bad behavior diagnosis on domestic environment, Energy Procedia 62 (2014) 246 -255 . 
[8] A. Foucquier, S. Robert, F. Suard, L. Stéphan, A. Jay, State of the art in building modelling and energy performances prediction: A review, Renewable and Sustainable Energy Reviews 23 (2013) 272 - 288.

[9] S. Prívara, J. Cigler, Z. Vána, F. Oldewurtel, C. Sagerschnig, E. Záceková, Building modeling as a crucial part for building predictive control, Energy and Buildings 56 (2013) 8-22.

[10] R. De Coninck, F. Magnusson, J. Åkesson, L. Helsen, Toolbox for development and validation of grey-box building models for forecasting and control, Journal of Building Performance Simulation (2015) 1-16.

[11] K. Yun, R. Luck, P. J. Mago, H. Cho, Building hourly thermal load prediction using an indexed ARX model, Energy and Buildings 54 (2012) 225 - 233.

[12] C. R. Touretzky, R. Patil, Building-level power demand forecasting framework using building specific inputs: Development and applications, Applied Energy 147 (2015) $466-477$.

[13] G. Ríos-Moreno, M. Trejo-Perea, R. Castañeda-Miranda, V. Hernández-Guzmán, G. Herrera-Ruiz, Modelling temperature in intelligent buildings by means of autoregressive models, Automation in Construction 16 (2007) 713 - 722.

[14] K. M. Powell, A. Sriprasad, W. J. Cole, T. F. Edgar, Heating, cooling, and electrical load forecasting for a large-scale district energy system, Energy 74 (2014) $877-885$.

[15] E. O'Dwyer, L. D. Tommasi, K. Kouramas, M. Cychowski, G. Lightbody, Modelling and disturbance estimation for model predictive control in building heating systems, Energy and Buildings 130 (2016) 532 - 545.

[16] Y. Kwak, J.-H. Huh, C. Jang, Development of a model predictive control framework through real-time building energy management system data, Applied Energy 155 (2015) $1-13$. 
[17] D. Kim, J. Cai, K. B. Ariyur, J. E. Braun, System identification for building thermal systems under the presence of unmeasured disturbances in closed loop operation: Lumped disturbance modeling approach, Building and Environment 107 (2016) $169-180$.

[18] E. Žáčeková, Z. Váňa, J. Cigler, Towards the real-life implementation of MPC for an office building: Identification issues, Applied Energy 135 (2014) 53 - 62.

[19] G. Reynders, J. Diriken, D. Saelens, Quality of grey-box models and identified parameters as function of the accuracy of input and observation signals, Energy and Buildings 82 (2014) 263-274.

[20] Meteonorm data, http://www.meteonorm.com, 2017. [Online; accessed 07April-2017].

[21] H. Madsen, Time Series Analysis, Chapman \& Hall/CRC, 2007.

[22] J. Smrekar, P. Potočnik, A. Senegačnik, Multi-step-ahead prediction of NOx emissions for a coal-based boiler, Applied Energy 106 (2013) 89 - 99.

[23] T. Lin, B. G. Horne, P. Tino, C. L. Giles, Learning long-term dependencies in NARX recurrent neural networks, IEEE Transactions on Neural Networks 7 (1996) 1329-1338.

[24] J. M. P. Menezes Jr., G. A. Barreto, Long-term time series prediction with the NARX network: An empirical evaluation, Neurocomputing 71 (2008) 3335 3343.

[25] M. T. Hagan, H. B. Demuth, M. Beale, Neural Network Design, PWS Publishing Co., Boston, MA, USA, 1996.

[26] Y. Bengio, Y. Grandvalet, No unbiased estimator of the variance of k-fold crossvalidation, J. Mach. Learn. Res. 5 (2004) 1089-1105.

[27] R. Kohavi, A study of cross-validation and bootstrap for accuracy estimation and model selection, in: Proceedings of the 14th International Joint Conference on 
Artificial Intelligence - Volume 2, IJCAI'95, Morgan Kaufmann Publishers Inc., San Francisco, CA, USA, 1995, pp. 1137-1143.

[28] J.-S. Chou, A. S. Telaga, W. K. Chong, G. E. G. Jr., Early-warning application for real-time detection of energy consumption anomalies in buildings, Journal of Cleaner Production 149 (2017) 711 - 722. 